\title{
ORGANIZAÇÃO DE SERVIÇOS DE CAPELANIA HOSPITALAR: UM ESTUDO BIBLIOMÉTRICO
}

\author{
Organization of Hospital Chaplaincy Services: a bibliometric study \\ Organización de Servicios de Capellanía Hospitalaria: un estudio bibliométrico
}

Rosana Chami Gentil ${ }^{1}$

Beatriz Pinheiro da Guia

Maria Cristina Sanna ${ }^{3}$

\section{RESUMO}

Estudo bibliométrico que objetivou identificar a produção científica sobre Capelania Hospitalar, classificá-la segundo data de publicação, titulação dos autores, procedência institucional e geográfica dos trabalhos, tipo de texto e descritores de indexação dos trabalhos, além de organizar as palavras-chave em um mapa conceitual. Foram encontradas 772 publicações das quais 64 se referiam ao objeto de estudo. A análise compreensiva dos textos revelou que 29 títulos foram produzidos de 1977 a 2008, na Austrália, Canadá, Estados Unidos, Inglaterra e Portugal. Houve maior concentração de títulos em revistas especializadas em cuidado pastoral, embora a produção se estenda por periódicos de temática variada. Concluiu-se que a produção científica na área é recente, localizada fora do Brasil, com forte influência da Joint Comission on Accreditation of Healthcare Organization. São variadas as titulações dos autores, e há evidências de que se trata de uma área do conhecimento em construção, dada a variedade de descritores.

Palavras-chave: Assistência Religiosa. Organização e Administração. Indicadores Bibliométricos

\begin{abstract}
This bibliometric study is aimed at identifying the scientific production on Hospital Chaplaincy and classifying it according to the date of publication, the authors' degree of education, institutional and geographical provenance of the work, type of text and index keywords, as well as organizing the keywords in a conceptual map. 772 publications were found, 64 of which related to the object of study. The comprehensive analysis of the texts revealed that 29 titles had been produced from 1977 to 2008 in Australia, Canada, the USA, the UK and Portugal. The majority of titles concentrated on magazines specializing in pastoral care, although the production also encompasses journals dedicated to various themes. The conclusion is that the scientific production in the area is recent and located out of Brazil, and strongly influenced by the Joint Commission on Accreditation of Healthcare Organization. The authors' degree of education is varied, and evidence was found that this knowledge area is under construction, in light of the various keywords.
\end{abstract}

Keywords: Pastoral Care. Organization and Administration. Bibliometric Indicators

\section{Resumen}

El presente estudio bibliométrico tuvo el objetivo de identificar la producción científica sobre Capellanía de Hospital, clasificarla según la fecha de publicación, nivel de educación de los autores, procedencia institucional y geográfica de los trabajos, tipo de texto y palabras clave de indexación de los trabajos, además de organizar las palabras claves en un mapa conceptual. Se encontraron 772 publicaciones, de las cuales 64 se referían al objeto de estudio. El análisis amplio de los textos determinó que 29 títulos habían sido producidos entre 1977 y 2008, en Australia, Canadá, EE.UU., Inglaterra y Portugal. Los títulos consistieron principalmente en revistas especializadas en cuidado pastoral, sin embargo la producción incluya también periódicos de temática variada. Se concluyó que la producción científica en el área es reciente, ubicada fuera de Brasil, y tiene fuerte influencia de la Joint Commission on Accreditation of Healthcare Organization (Comisión Conjunta de Acreditación de Organizaciones de Cuidados con la Salud). El nivel de educación de los autores es variado, y hay evidencias de que se trata de un área del conocimiento bajo construcción, dada la variedad de palabras clave.

Palabras clave: Cuidado Pastoral. Organización y Administración. Indicadores Bibliométricos

${ }^{1}$ Enfermeira. Mestre em Enfermagem. Doutoranda pela Universidade Federal de São Paulo. Membro do GEPAG- Grupo de Estudos e Pesquisa em Administração e Gerenciamento em Saúde eEnfermagem do departamento de Enfermagem da UNIFESP.Docente da UniversidadeSanto Amaro.São Paulo-SP.Brasil. E-mail:enfair@uol.com.br,Mestre em Educação, Arte e História da Cultura pela Universidade Mackenzie. Membro do GEPAG - Grupo de Estudos e Pesquisa em Administração em Saúde e Gerenciamento em Enfermagem do Departamento de enfermagem da UNIFESP.Vinculação Institucional com o Centro UniversitárioSENAC. São Paulo-SP.Brasil. E-mail: beatriz_guia@hotmail.com ,'Enfermeira. Mestre e Doutora em Enfermagem pela Escola de Enfermagem da Universidade de São Paulo, com Pós-doutorado pela Escola de Enfermagem Anna Nery da Universidade Federal do Rio de Janeiro. Pesquisadora Independente. Orientadora Credenciada junto à Pós-Graduação da Universidade Federal de São Paulo - UNIFESP. Membro do GEPAG - Grupo de Estudos e Pesquisa em Administração em Saúde e Gerenciamento em Enfermagem do Departamento de enfermagem da UNIFESP. São Paulo - SP. Brasil. E-mail: mcsanna@uol.com.br 


\section{INTRODUÇÃO}

Capelania Hospitalar é uma prestação de serviço religioso ministrado aos enfermos em hospitais da rede pública ou privada, garantido por lei federal e leis estaduais, como previsto na Constituição Brasileira de 1988, nos seguintes termos: "é assegurada, nos termos da lei, a prestação de assistência religiosa nas entidades civis e militares de internação coletiva" (CF art. $\left.5^{\circ}, \mathrm{VII}\right){ }^{1}$

Apenas onze anos após a promulgação da Constituição, em 1999, foi publicado o Decreto $n^{\circ} 44395$ que regulamentou a Lei no 10.066, de $1998^{2}$ que dispõe sobre a prestação de assistência religiosa nas entidades hospitalares públicas e privadas civis e militares de internação coletiva.

Nas entidades hospitalares públicas e privadas, a Lei nº 9.982 de 2000, regulamentou a prestação de assistência religiosa, assim dispondo:

"Art. $1^{\circ}$ Aos religiosos de todas as confissões assegura-se o acesso aos hospitais da rede pública ou privada, bem como aos estabelecimentos prisionais civis ou militares, para dar atendimento religioso aos internados, desde que em comum acordo com estes, ou com seus familiares, no caso de doentes que já não mais estejam no gozo de suas faculdades mentais. Art. $2^{\circ}$ Os religiosos chamados a prestar assistência nas entidades definidas no art. $1^{\circ}$ deverão: em suas atividades, acatar as determinações legais e normas internas de cada instituição hospitalar ou penal, a fim de não por em risco as condições do paciente ou a segurança do ambiente hospitalar ou prisional".3

Essa assistência pode ser prestada por diferentes agentes de cuidado pastoral, dentre os quais está o capelão. Este, fora do nosso país, como nos EUA e Inglaterra, faz parte da equipe interdisciplinar de assistência ao paciente, desenvolvendo atividades de apoio espiritual, realizando acompanhamento da evolução do paciente e também registrando seu trabalho no prontuário do cliente, além de ter estabelecidas formalmente suas atribuições e competências. ${ }^{4}$

Historicamente o termo "capelania" foi criado na França, em 1700 porque, em tempos de guerra, o rei costumava mandar para os acampamentos militares, uma relíquia dentro de um oratório, que recebia o nome de "Capela". Essa capela ficava sob a responsabilidade do sacerdote, conselheiro dos militares. Em tempos de paz, a capela voltava para o reino, ainda sob a responsabilidade do sacerdote, que continuava como líder espiritual do rei, e assim ficou conhecido por capelão. Com o tempo, o serviço de capelania se estendeu aos parlamentos, colégios, cemitérios e prisões. ${ }^{5}$

Nunca o interesse por espiritualidade e saúde esteve tão presente, como nos últimos anos. Vários artigos científicos evidenciam ${ }^{6,7,8}$ que as pessoas que possuem fé e uma religião têm aceitação maior do tratamento de saúde, da hospitalização e aumento da imunidade, além de menores índices de depressão e ansiedade, enfrentando a enfermidade com mais esperança e força, tendo melhor qualidade de vida e um propósito para viver.

Silva, Porto e Figueiredo ${ }^{9}$ chamam à atenção para a valorização da qualidade do cuidado incluindo o reconhecimento dos direitos do cliente, de sua subjetividade e referências culturais.

De acordo com Saad e Guimarães ${ }^{8,10}$ vários trabalhos publicados documentam a influência da espiritualidade no tratamento de doenças. É plenamente reconhecido que a saúde dos indivíduos é determinada pela interação de fatores físicos, mentais, sociais e espirituais, pois, de acordo com a Organização Mundial de Saúde $(\mathrm{OMS})^{11}$ o bem-estar espiritual é uma dimensão do estado de saúde, junto às dimensões biológicas, psíquicas e sociais.

Dessa forma, e por essa necessidade, cresce o número de capelães nos hospitais brasileiros, cuja missão é oferecer apoio espiritual, emocional e social, aos enfermos, seus cuidadores e profissionais da saúde. Assim, a capelania hospitalar vem restabelecer essa interação entre espiritualidade e saúde, influenciando, como afirma Saad, ${ }^{8}$ na rápida recuperação dos pacientes internados.

Os hospitais que contam com esse serviço são mais bem conceituados junto à clientela por terem uma visão do cuidado integral ao paciente, seus familiares e profissionais da saúde. $^{5}$

Além disso, nos Estados Unidos a Joint Commission on Accreditation of Healthcare Organization (JCAHO), organização privada que estabelece padrões para a operação de instalações e serviços de saúde, ajudou a definir o cuidado espiritual profissional, expandindo a categoria do cuidado espiritual em sua linha de trabalho, ${ }^{4}$ atribuindo valor à existência desse trabalho na acreditação de instituição de saúde. As instituições brasileiras que se submetem à acreditação pela JCAHO também são avaliadas nesse quesito.

Desde 1969, a JCAHO valoriza a assistência espiritual, porém os "guidelines" só foram revisados de forma significativa em 1990, com a declaração dos direitos do paciente. ${ }^{12} \mathrm{Em}$ 1996, a ICAHO determinou que os hospitais demonstrassem respeito pelo aconselhamento pastoral como atividade. Essa frase foi então substituída por "cuidado pastoral e serviço espiritual" em 1999, porque os lideres da capelania argumentaram que essa expressão refletia melhor o seu trabalho. No "guideline" de 1999, a JCAHO mencionou 0 "departamento de serviço pastoral" e "pessoa pastoral externa". Em 2003, a mesma instituição declarou que "o paciente tem direito fundamental de considerar, salvaguardado o cuidado, sua dignidade pessoal, respeito por sua cultura, psicossocial e valores espirituais"..$^{12} \mathrm{~A}$ esse propósito, esses estudiosos ${ }^{12}$ do assunto declararam que o hospital deverá "demonstrar respeito sobre as necessidades do paciente, 
incluindo a necessidade do cuidado pastoral ou outros serviços espirituais".

Diante da problemática apresentada, resolveuse investigar como o assunto "Capelania Hospitalar" se apresentava na literatura científica sobre o tema, dado que, em nosso país, apesar da liberdade de culto e do sincretismo religioso que impregna nossa cultura, não há valorização do cuidado espiritual a ponto de justificar a instalação de serviços de capelania hospitalar formalmente instituídos. Em contraste com essa realidade, movimentos pela humanização dos serviços de saúde têm sido desenvolvidos recebendo, inclusive, incentivos do Ministério da Saúde, entre outros. Nessa linha, ações de Acreditação de Serviços de Saúde, passaram a observar mais atentamente esses esforços, ainda que sejam motivadas por padrões internacionais. Isso faz crer que há uma tendência, ainda que incipiente à formalização de serviços dessa natureza nos hospitais brasileiros, o que justifica a busca de literatura científica a respeito, mesmo que não tratem da nossa realidade. 0 resultado desse estudo poderá auxiliar no aprofundamento posterior da questão e na indicação de conceitos e modelos que possam subsidiar posteriormente a instalação desses serviços em nosso país.

Como variáveis do estudo foram selecionados: fontes difusoras de trabalho; evolução cronológica da produção científica; produtividade de autores de instituições; propagação das publicações científicas; e crescimento do conhecimento no campo da ciência sobre capelania. 0 estudo dessas variáveis se torna relevante porque remete à possibilidade de obter índices qualitativos, por meio da análise de cada artigo - pertinência do seu conteúdo, abrangência temática, e quantitativos - quantidade de periódicos, autores, produção científica.

Assim, considerando que a capelania hospitalar vem se tornando um serviço emergente nas instituições de saúde brasileiras, que carece da implantação de uma organização ou instituição formal e já está instalada em outros países, considerou-se oportuno explorar o conhecimento disponível sobre o assunto.

\section{OBJ ETIVOS}

- Identificar a produção científica nacional e internacional sobre os Serviços de Capelania Hospitalar;

- Classificar a produção científica encontrada segundo ano de publicação, titulação dos autores, procedência institucional e geográfica, tipo de texto e descritores de indexação dos trabalhos; e

- Classificar as palavras-chave utilizadas pelos autores nos trabalhos analisados em um mapa conceitual, relacionandoas de forma compreensiva em classes temáticas.

\section{MÉTODO}

Estudo descritivo, desenvolvido na perspectiva da bibliometria. Foram consultadas as bases de dados LILACS e MEDLINE da Biblioteca Virtual em Saúde (BVS), em dezembro de 2008. Não foi adotada nenhuma restrição de tempo para as publicações.

Para a busca, primeiro consultaram-se as bases com os descritores indicados pelo DeCS "Hospital Chaplaincy Service", quando foram encontradas 772 publicações. Após o refinamento com outros descritores mais específicos - "Hospital" e "Organização" combinados e "Joint Commission on the Accreditation of Health Care Organizations - JCAHO" ficou-se com 374 indicações de artigos de periódicos científicos. Em seguida, foram lidos os títulos e, quando havia, os resumos (41,97\% dos textos os tinham), para identificação da pertinência dos textos ao tema em foco, o que resultou em 64 indicações.

Os 64 artigos na íntegra foram então obtidos através da Biblioteca Regional de Medicina da OMS, copiados e organizados fisicamente em pastas, por ordem cronológica de publicação. Por fim, os artigos foram lidos em busca das informações sobre as variáveis de estudo, que foram anotadas em uma planilha Excel, com a qual se apurou as frequências simples e relativas de cada uma. Feito isso, buscou-se arrolar as palavras-chave de cada um dos artigos, para fins de estudos bibliométricos.

0 termo bibliometria é utilizado para quantificar os processos de comunicação escrita e o emprego de indicadores bibliométricos para medir a produção científica. Araújo ${ }^{13}$ argumenta que, como técnica quantitativa e estatística de medição dos índices de produção e disseminação do conhecimento científico (inicialmente conhecida como bibliografia estatística), esta técnica surgiu no início do século XX com o intuito de estudar e avaliar as atividades de produção e comunicação científica.

Como aplicação técnica estatística para análise quantitativa da informação, o termo foi criado pelo renomado estudioso da documentação, Paul Otlet, ${ }^{13} \mathrm{em}$ 1934, embora somente tenha se popularizado no final da década de 1960. Seu foco é a utilização de métodos quantitativos na busca por uma avaliação objetiva da produção científica.

Justifica-se sua utilização, pois analisa e avalia as fontes difusoras dos trabalhos, a evolução cronológica da produção científica, a produtividade de autores e instituições, a propagação das publicações científicas, 0 crescimento de qualquer campo da ciência e o impacto das publicações diante da comunidade científica internacional.

Pensando em um conhecimento ainda em construção, utilizou-se a metodologia de mapa conceitual para organizar as palavras-chaves, buscando relações entre conceitos temáticos ligados por essas palavras. ${ }^{14}$ 
A abordagem dos mapas conceituais está embasada em uma teoria construtivista. Estes são utilizados para facilitar 0 aprendizado e o entendimento do conteúdo sistematizado, representando-o em algo significativo para quem estuda ou pesquisa, sendo muito utilizado para organizar e representar o conhecimento. ${ }^{14}$

Buscou-se encontrar alguma afinidade entre as palavras-chave relacionadas nos artigos pesquisados a partir de uma que foi considerada a principal, que é Chaplaincy, não só por sua incidência entre os artigos mas, também, por ser 0 tema do presente trabalho e por ter um conceito claro. Encontrando identidade por afinidade temática conceitual, as palavras-chave foram agrupadas a partir da principal, em uma organização sistemática em classes temáticas, mas não de forma hierárquica.

Chegou-se às classes temáticas a partir da relação intrínseca entre as palavras-chave. Algumas tinham um conceito bem definido, assim como incidência representativa. Observou-se que 3 tinham valor formativo para o exercício da Capelania; 6 apresentavam valor religioso e 3, espiritual, dentro do universo estudado; 5 remetiam a um valor profissional (de recursos humanos); 2 representavam a quem se destina a Capelania e 6 mostravam uma relação com os aspectos organizacionais desencadeados pela Capelania. Foi necessário, ainda, fazer uma relação com o termo Chaplain, radical de Chaplaincye mais 4 termos que representavam aplicações ou processos desencadeados pela prática da Capelania. Algumas palavras, 14 no total, não encontraram seu lugar nessas relações e foram arroladas em um grupo sem classificação temática, para ficarem representadas no mapa, mas sem valor conceitual.

Para o recorte temporal da divisão dos períodos compreendidos, entre a publicação dos periódicos, foram usadas as transformações no critério da JCAHO.

\section{RESULTADOS E DISCUSSÃO}

Das 64 publicações estudadas, $70 \%$ (45) usaram palavras-chave diferentes, o que demonstra que o tema em foco é um conhecimento ainda em construção. Ressalte-se que $30 \%$ (19) dos trabalhos, anteriores a 2001, não exibiam palavras-chave.

Quadro 1: Palavras-chave utilizadas pelos autores nos trabalho analisados*.

\begin{tabular}{|lrlr|}
\hline Palavra-Chave & Incidência & Palavra-Chave & Incidência \\
\hline Alternative Healing & 1 & Interdisciplinary Team & 2 \\
Caregivers & 1 & Interventions & 1 \\
Chaplain & 6 & Measurement & 1 \\
Chaplaincy & 7 & Networking & 1 \\
Chaplaincy Program & 1 & Organizational Objectives & 1 \\
Chaplaincy Services & 1 & Outcomes & 1 \\
Clinical & 1 & Palliative Care & 1 \\
Clergy & 1 & Pastoral Care \\
Education & 1 & Patient Rights \\
Epiritual Care & 1 & Professional Standards \\
Ecumenical & 1 & Provision of Health care Services & 5 \\
Ethical & 1 & Referrals & 1 \\
European Union & 1 & Religion & 1 \\
General Health Questionnaire & 1 & Religious Needs \\
Health Personnel & 1 & Science & 2 \\
Healthcare Chaplaincy & 2 & Spiritual Care \\
Hospice & 1 & Spiritual Needs \\
Hospital & 2 & Spirituality & 1 \\
Hospital Chaplaincy & 2 & Staff Support & 1 \\
Hospital Medicine & 1 & Stress & 3 \\
Hospital Restructuring & 1 & Theological \\
Hospitalized Patients & 1 & Training & 1 \\
Health care reform & 2 & & 4 \\
Innovative Solutions & 1 & & 1 \\
\hline
\end{tabular}

* 0 número de palavras-chave por artigo variaram de um a cinco. 
No Quadro 1 observa-se, que as palavras-chave mais usadas foram: "Chaplaincy", em 7 artigos, "Chaplain", em 6, e "Pastoral Care" e "Religion", em 5 artigos.

Como se pode observar no Quadro 1, há uma grande variabilidade e espectro de abrangência de palavras-chave, que vão desde os processos de trabalho, assistência, ensino e gerência, formação profissional até os religiosos e espirituais, 0 que demonstra ser um conhecimento ainda em construção.
Em uma primeira organização, o mapa conceitual com as palavras-chave encontradas nos artigos estabeleceuse da forma como é apresentado a seguir, seguindo uma organização a partir da similitude do sentido dos termos ou da relação morfológica das palavras. A ideia do mapa foi organizar e reunir todas as palavras coletas nos textos, sem pretensão de aprofundamento de estudos terminológicos ou linguísticos.

Mapa conceitual: Relação do termo Chaplaincy com palavras-chave mencionadas nos artigos pesquisados.

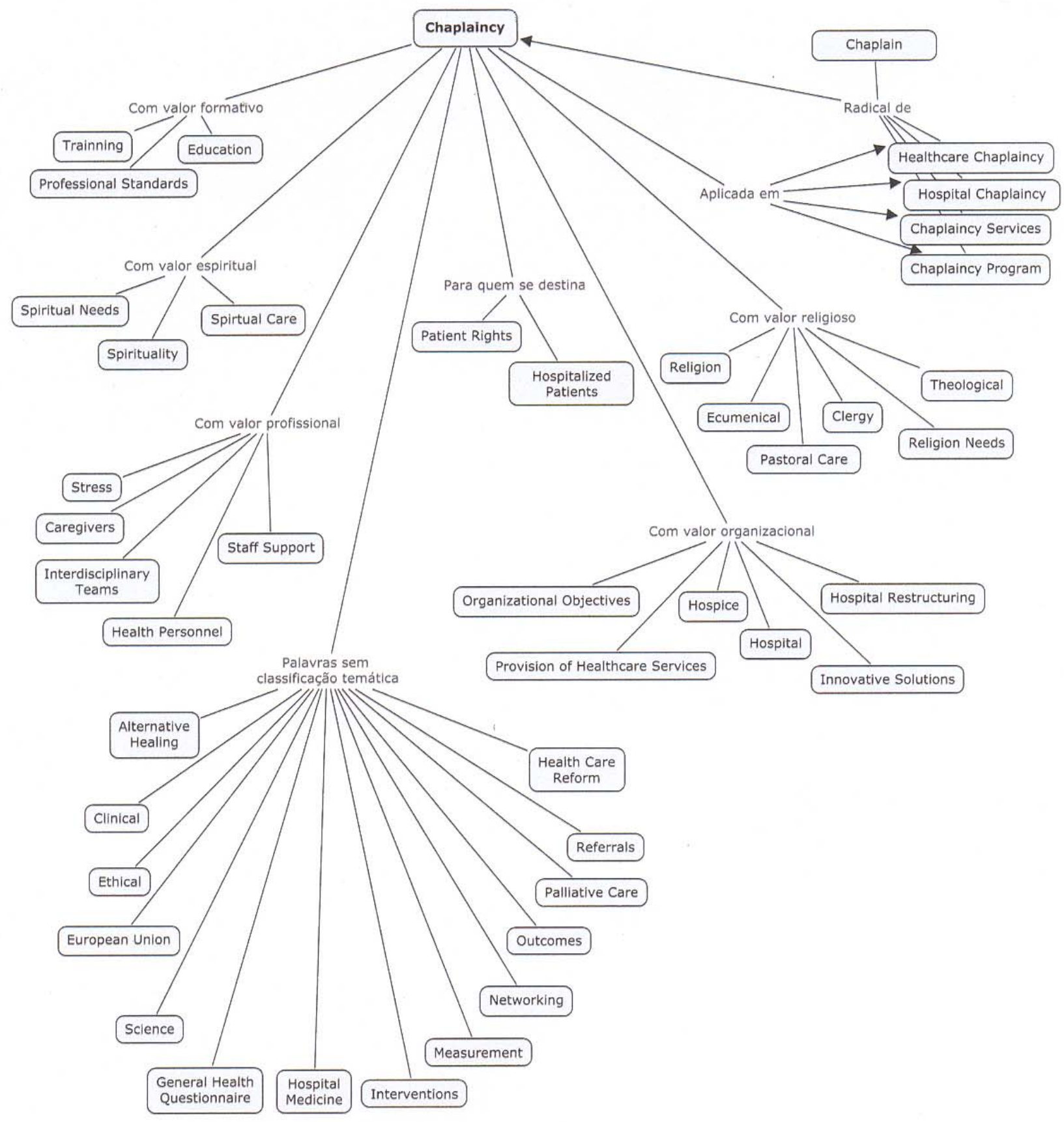


A partir do mapa conceitual, pode-se comentar alguns aspectos como, por exemplo: decidiu-se criar duas classes: em uma classe as palavras representam os valores religiosos ou estão relacionadas a uma prática religiosa e, em outra, representam os valores espirituais, não necessariamente ligados ao aspecto religioso.

Outro ponto importante é que algumas palavras não poderiam ser consideradas palavras-chave, por terem vários significados ou, ainda, ser um adjetivo ou um processo não relacionado às outras classes. Optou-se, então, em reunir todas essas palavras em um grupo sem classificação temática, apenas para efeito de organização do mapa e para não se perder nenhuma das palavras recolhidas na pesquisa.

Algumas palavras contêm o radical "chaplain", o que possibilitou reuni-las em um grupo de quatro palavras-chave. Por outro lado, o termo "chaplaincy" aparece relacionado a este mesmo grupo, tendo-se considerado sua aplicação enquanto prática ou processo

Tabela 1 Distribuição dos trabalhos sobre Capelania Hospitalar, nos períodos em que foram publicados, segundo respectivos periódicos, São Paulo, 2009.

\begin{tabular}{|c|c|c|c|c|c|c|}
\hline Periódicos & & & Período & & & Total \\
\hline & $\begin{array}{l}1969:- \\
1990 \\
\end{array}$ & $\begin{array}{l}1991:- \\
1996 \\
\end{array}$ & $\begin{array}{l}1997 ! \\
1 \\
1999 \\
\end{array}$ & $\begin{array}{l}20001- \\
12003 \\
\end{array}$ & $\begin{array}{l}2004:- \\
12008 \\
\end{array}$ & \\
\hline $\begin{array}{l}\text { American Health Consultants - } \\
\text { Healt Care Bench Marks }\end{array}$ & & & & 1 & & 1 \\
\hline Cristian Bioethics & & & & 1 & & 1 \\
\hline $\begin{array}{l}\text { Dimensions of Critical Care } \\
\text { Nursing }\end{array}$ & & & & & 1 & 1 \\
\hline Health Care Management Review & 1 & & & & & 1 \\
\hline Health Progress & & 1 & & & 1 & 2 \\
\hline Health Service Journal & & & & & 1 & 1 \\
\hline Hosp Prog & 1 & & & & & 1 \\
\hline Hospital Peer Review & & & & 1 & & 1 \\
\hline Hospital Progress & 2 & & & & & 2 \\
\hline $\begin{array}{l}\text { HOSPITAL TOPICS: Research } \\
\text { and Perspectives on Healthcare }\end{array}$ & & & & & 1 & 1 \\
\hline $\begin{array}{l}\text { International Journal of Psychiatry } \\
\text { in Medicine }\end{array}$ & & & & & 1 & 1 \\
\hline JONA & 1 & & & & & 1 \\
\hline Journal of Health Care Chaplaincy & 1 & 2 & & 2 & 3 & 8 \\
\hline $\begin{array}{l}\text { Journal of Health Protection } \\
\text { Management }\end{array}$ & & & 1 & & & 1 \\
\hline Medical Antropology & & & & & 1 & 1 \\
\hline Medical Records News & & 1 & & & & 1 \\
\hline Medscape General Medicine & & & & & 1 & 1 \\
\hline MEDSURG Nursing & & & & & 1 & 1 \\
\hline Nursing Management & & & & & 1 & 1 \\
\hline Palliative Medicine & & & & & 1 & 1 \\
\hline Psycho-oncology & & & & 1 & & 1 \\
\hline Servir & 1 & & & & 1 & 2 \\
\hline Southern Medical Journal & & & & & 7 & 7 \\
\hline The Journal of Clinical Ethics & & 1 & & & & 1 \\
\hline $\begin{array}{l}\text { The Journal of Pastoral Care \& } \\
\text { Counseling }\end{array}$ & 9 & 3 & 3 & 4 & 3 & 22 \\
\hline The Medical Journal of Australia & 1 & & & & & 1 \\
\hline Work & & & & & 1 & 1 \\
\hline Total & 17 & 8 & 4 & 10 & 25 & 64 \\
\hline
\end{tabular}

Na Tabela 1, o periódico "Journal of Pastoral Cared Counseling" foi o que apresentou maior número de artigos escritos (22), 34,37\%, seguido do "Journal of Health Care
Chaplaincy" (8), 12,50\%. Ambos são periódicos dirigidos ao tema em foco no presente estudo. Já o "Southem Medical Journal , com (7) 10,93\% citações, apresenta temática variada. 
0 "Journal of Pastoral Care \& Counseling" se deu a partir da junção do "Journal of Pastoral Care (JPC)" que foi fundado em 1950; em 1967, estabeleceu-se na sede da "Association for Clinical Pastoral Education - (ACPE). Em 1982, o "Bulletin - American Protestant Hospital Association" juntouse ao JPC, que em 2003 passou a se chamar "Journal of Pastoral Care \& Counseling". ${ }^{15}$

0 periódico "Journal of Health Care Chaplaincy" foi fundado em 1969, e o "Southem Medical Journal", em 1908, há mais de 100 anos. $^{16}$

A década de 2000 a 2010, embora ainda inacabada, foi a que concentrou o maior número de trabalhos, (35) $54,68 \%$, nesta área temática. Como se observou entre os períodos 1969 a 1990, houve um importante número de publicações (17), coincidindo com a valorização da assistência espiritual pela JCAHO. No período entre 1991 a 1996, o que impulsionou as publicações (8) foi a declaração dos direitos do paciente. A partir dessa data, a JCAHO determinou que os hospitais demonstrassem respeito pelo aconselhamento pastoral. Mas, foi a partir de 1999, com os "guidelines" estabelecidos pela ICAHO sobre a assistência espiritual passando a ser um "Departamento de Serviço Pastoral" que as publicações voltaram a crescer novamente.

Com a declaração de que "o paciente tem direito fundamental de considerar salvaguardado o cuidado, sua dignidade pessoal, respeito por sua cultura, psicossocial e valores espirituais", enunciada em 2003, o número de publicações atingiu o patamar de 25 títulos, até 0 ano de 2008.

Observou-se também, pela diversidade de periódicos em que as publicações se distribuíram (29), que se trata de um conhecimento de natureza interdisciplinar, pois abrange várias áreas como: administração hospitalar, organização de serviços, recursos humanos, políticas públicas, ética, entidades de classe, especialidades de atenção médica e aspectos clínicos e administrativos de enfermagem.

Tabela 2 Distribuição dos tipos de trabalhos sobre Capelania Hospitalar, segundo países nos quais os periódicos foram editados, São Paulo, 2009.

\begin{tabular}{|c|c|c|c|c|c|c|}
\hline \multirow[b]{2}{*}{ País } & \multicolumn{5}{|c|}{ Tipo de Trabalho } & \multirow[b]{2}{*}{ Total } \\
\hline & Artigos* & Anais & Editorial & Entrevista & $\begin{array}{c}\text { Não } \\
\text { Identificado }\end{array}$ & \\
\hline Austrália & 2 & & & & & 2 \\
\hline Canadá & 3 & & & & & 3 \\
\hline EUA & 43 & & 5 & 2 & 3 & 53 \\
\hline Grécia & 1 & & & & & 1 \\
\hline Inglaterra & 3 & & & & & 3 \\
\hline Portugal & 1 & 1 & & & & 2 \\
\hline Total & 53 & 1 & 5 & 2 & 3 & 64 \\
\hline
\end{tabular}

Na Tabela 2 constata-se que foi os EUA o país que mais produziu artigos sobre o tema, (53) $82,81 \%$, seguido de Canadá e Inglaterra, com (3) 4,8\%.

Parece que esse resultado não é uma questão de modo de viver por serem protestantes, nem de ser um país mais antigo, mas sim de haver, nos EUA, centros que produzem mais conhecimento sobre esse tema.

Do total dos trabalhos, $82,81 \%$ (53) foram escritos em forma de artigos, sendo que 39,6\% (25) de artigos científicos, $29 \%$ (19) artigos originais, 9,37\% (6) de opinião e 7,81\% (5) de revisão.

0 Estado de New York, nos EUA, foi o local de origem geográfica de residência dos autores mais frequente, com 11 publicações, seguido por Illinois com cinco, Califórnia com quatro e Texas com três publicações.

As publicações eram de países da América do Norte, da Europa e da Oceania, a maioria escrita na língua inglesa, inclusive os publicados de proveniência grega; só 2 trabalhos provenientes de Portugal foram publicados em língua portuguesa. Um desses trabalhos foi publicado na forma de Anais, referente à aula magna da Faculdade de Medicina da Universidade de Lisboa, no "I Seminário Nacional de Espiritualidade: um desafio no Hospital".

Em relação ao número de autores por trabalho, a maioria (36) teve um autor apenas, o que pode indicar que a produção é realizada de forma isolada. Dezesseis trabalhos contaram com dois autores e sete com três autores. Três trabalhos, com nove, oito e sete autores, fizeram parte de um estudo multinstitucional, abrangendo a região metropolitana de New York, no período de 1994 e 1996, com 38.600 registros sobre as visitas de capelães a pacientes e suas famílias, em 13 instituições de cuidados à saúde, que objetivava saber o que realmente os capelães faziam.

0 autor que mais publicou artigos (8) foi o George F. Hanzo, Mdiv (Mestre no estudo de Divindades), MA, BCCLíder do cuidado e prática pastoral do "The Health Care Chaplaincy", seguido de Kathleen Galek, PhD, professora associada do "John Templeton Foundation" com 6 artigos: com 
5, Kevin J. Fannelly PhD, Director Associado do Centro de Pesquisa "The Health Care Chaplaincy", sendo que esses 3 autores também fizeram parte dos 3 trabalhos com maior número de autores.

Esse Centro de Pesquisa é um Centro de Estudos em New York, fundado em 1961, cuja missão é o avanço profissional do cuidado pastoral através da liderança visionária e excelência contínua e inovadora da pesquisa, educação e prática clínica.

A titulação dos autores variou bastante, tendose encontrado profissionais de saúde com nível de bacharel ou licenciado, mestres e doutores nas mais diversas áreas do conhecimento, e ministros de diferentes religiões, em um total de 31 diferentes credencial letters (letras que designam a titulação acadêmica) (Anexo 1).

As instituições de procedência dos artigos variaram entre hospitais (30), entidades de classe (15) e universidades (12). Observou-se que, diferentemente do Brasil, a produção científica sobre capelania é proveniente principalmente da prática clínica nos hospitais e, em menor escala, das entidades de classe e das universidades.

Em 1997 o periódico The Journal of Pastoral Care trouxe um estudo $0^{12}$ sobre as competências para o trabalho da assistência espiritual pela "Clinical Pastoral Education"; em 2000, o periódico American Health Consultants fez a primeira menção à Joint Commission on Accreditation of Healthcare Organizations, com o artigo intitulado" How to meet JCAHO's pastoral care standards". Nesse mesmo ano, mais dois artigos sobre a JCAHO foram publicados, no periódico Journal of Pastoral Care intitulados "What Five Clinical Pastoral Education Residents Discovered from a ICAHO Review" e "Utilizing a JCAHO Review in the Education of Clinical Pastoral Education CPE Residents", o que indicou ter sido, nesta época, o início da inclusão do quesito "capelania" para acreditação dos serviços de saúde, por aquela organização, explicando esse aumento da produção científica a partir de então.

\section{CONCLUSÃO}

Foram identificadas 64 publicações sobre o tema, nenhuma de origem brasileira. Os resultados indicaram que a maioria das publicações era oriunda de países em que a Capelania Hospitalar está formalmente instituída, como os Estados Unidos da América, com a maior representatividade de procedência e sede dos veículos de publicação.

Os textos analisados variaram de artigos de opinião a produtos de pesquisa, algumas com grande espectro de abrangência. Doutores, mestres e especialistas foram os autores da maioria dos trabalhos, mas também foram encontrados enfermeiros, religiosos, médicos e cientistas sociais, sem qualquer outra titulação. A função exercida pelos autores, assim como sua procedência institucional e geográfica foi bem variada, indicando que o tema tem merecido a atenção de diferentes estudiosos.
A produção é recente, restrita aos últimos dez anos, com aumento crescente na primeira década do século XXI, com forte influência da Joint Commission on Accreditation of Healthcare Organization (JCAHO's) nas publicações.

As palavras-chave de indexação dos trabalhos também variaram muito, o que é evidência de que se trata de uma área do conhecimento ainda em estado incipiente de construção. Do termo "Chaplaincy" deriva a maior parte de palavras-chave encontradas. Sete agrupamentos derivam deste radical e se referem aos valores formativo, espiritual, religioso, profissional e organizacional. Um grupamento externo a essa estrutura foi constituído por palavras-chave que se referiam a quem se destinavam os textos - direito dos pacientes e pacientes hospitalizados, e locais de exercício da capelania.

0 tema estudado não é específico da ciência de Enfermagem. Trata-se de fenômeno caracterizado por área de ação interdisciplinar que, no entanto, contempla a Enfermagem como corpo social e também como produtora de conhecimento. Considerando-se o papel destacado que a Enfermagem exerce na administração de serviços de saúde, principalmente em hospitais, e seu preparo acadêmico, bem como suas pesquisas sobre o tema, é possível encontrar aproximação entre os processos de trabalho em enfermagem e a organização de condições para a prestação de assistência espiritual.

A Enfermagem tem desempenhado o papel de identificadora de necessidades de assistência e de encaminhadora para serviços e/ou profissionais, quando necessário e fora de seu espectro de atuação. Assim, a organização de serviços de capelania hospitalar interessa sobremaneira a esses profissionais e estudar esse tema estáse tornando cada vez mais oportuno, dado os movimentos para a instalação desses serviços nas instituições hospitalares em nosso país. 0 presente estudo teve a finalidade de contribuir para esse intento.

\section{NOTA}

Titulação dos autores (credencial letters)

B.N. - Bacharel em Enfermagem

CCRN - Enfermeira especialista em cuidados críticos

CNRN - Certified Neuroscience Registered Nurse

Dmin - Doutorado em Ministério

ED. D. - Doutor em Educação

$\mathrm{Fr}-$ Frei

Mdiv. - Mestre em Divindade

MPh - Mestre em Filosofia

MD - Médico

MS - Mestre em Ciências

MSN - Mestre em Enfermagem

MTh - Mestre em teologia

PhD-Doutor

RN - Enfermeira

$\mathrm{Sr}-$ Irmã

SC-Cientista Social

ThM - Mestre em Teologia 


\section{REFERÊNCIAS}

1. Lei n. 7.672, de 23 de junho de 1988. Dispõe sobre o Serviço de Assistência Religiosa nas Forças Armadas. [on-line] jun 1988; [citado 2008 out 8]. Disponível em: http://stbcaxiense.com.br/estudos/ capelania.htm.

2. Lei n. 10.066, de 21 de julho de 1998. Dispõe sobre a prestação de assistência religiosa nas entidades civis e militares de internação coletiva situada no território do Estado. Diário Oficial do Estado de São Paulo[online]. jul 1998; [citado 2008 out 5]. Disponível em: http://capelão.com/ pagina.

3. Lei n. 9.982, de 14 de julho de 2000. Dispões sobre a prestação de assistência religiosa nas entidades hospitalares públicas e privadas, e dá outras providências. Diário Oficial da República Federativa da União.

[on-line] jul 2000; [citado 2008 out 30] Disponível em: www.planalto.gov.br.

4. Ford T, Tartaglia A. The development, status, and future of healthcare chaplaincy. Southern Med J. 2006; 99(6): 156-59

5. Capelania Hospitalar [on-line] 2007 set; [citado 2007 set 10] Disponível em: www.capelaniahospitalar.com.br.

6. Ismael PS. Capelania Hospitalar Evangélica e o sagrado: um meio de reelaboração do sofrimento [dissertação]. São Paulo (SP): Universidade Presbiteriana Mackenzie; 2006.

7. Selli L, Alves JS. 0 cuidado espiritual ao paciente terminal no exercício da enfermagem e a participação da bioética. Revista Bioethikos, Centro Universitário São Camilo 2007; 1(1): 43-52.

8. Saad M, Masiero D, Battistella LR. Espiritualidade baseada em evidências. Acta Fisiatr 2001; 8(3): 107-12.

9. Silva RCL, Porto IS, Figueiredo NMA. Reflexões acerca da assistência de enfermagem e o discurso de humanização em terapia intensiva. Esc Anna Nery. 2008;12 (1):156- 59.

10. Guimarães HP, Avezum A. 0 impacto da espiritualidade na saúde física. Rev Psiquiatr Clin. 2007; 34 (supl 1): 88-94.

11. World Health Organization- WHO. Division of Mental Health and Prevention of Substance Abuse. WHOQOL and Spirituality, Religiousness and Personal Beliefs-SRPB: Report on WHO consultation. Geneve; 1998.

12. Cadge W, Freese J, Christakis N. The provision of hospital chaplaincy in the United. Southern Med J; 2008; 101(6): 626-30.

13. Araujo, C A. Bibliometria: evolução histórica e questões atuais. Em questão [on- line] 2006 jan/jun [citado 2009 abr 15]; 12(1). Disponível em: http://www.seer.ufrgs.br/index.php/EmQuestao/article/view/16/5.

14. Novak, JD, Cañas AJ. The theory underlying concept maps and how to construct them[on-line]; [citado 2008 ago 29]; Disponível em: http:// cmap.ihmc.us/Publications/ResearchPapers/ TheoryUnderlyingConceptMaps.pdf. 